Review Article

\title{
PHARMACY PROFESSIONS IN INDIA DURING COVID-19 PANDEMIC: PRESENT STATUS, FUTURE CHALLENGES AND A WAY FORWARD
}

\author{
VIGNESH M. ${ }^{1}$, GANESH G. N. K. ${ }^{*}$ \\ 1Department of Pharmaceutical Regulatory Affairs, JSS College of Pharmacy, JSSAHER, Ooty, 643001, 2Department of Pharmaceutics, JSS \\ College of Pharmacy, JSSAHER, Ooty, 643001 \\ Email: gnk@jssuni.edu.in
}

Received: 10 Sep 2020, Revised and Accepted: 22 Oct 2020

\begin{abstract}
People in every country became exposed to COVID-19 pandemic and cannot able to find a right solution and strategies to overcome from it. Pharmacy is the most important, dynamic and versatile health care profession in the world, whereas its scope and importance are always being emerging at any situation. Pharmacy professionals (PPs) working proactively for the public even in this pandemic situation. Since dependency is high, the responsibility and preference also high for PPs especially in this pandemic situation. Current status in pharmacy education and emerging future challenges of PPs in all aspects, particularly in this pandemic situation were addressed based on observational studies among various pharma industries and published news of Pharmacy Council of India (PCI). While in the development phase it has crossed many barriers, not only in the economic level, but also involves regulations, duration, process controls, legal hurdles and situational defects. The purpose of this review discusses the evolution and updates in pharmacy, education, pharmacy practice, regulations, and types of challenges along with recommendations for PPs in India in light of the COVID-19 pandemic.
\end{abstract}

This review was carried out to summarize knowledge about the updates and challenges in pharmacy professions in all aspects. Sources were retrieved from relevant guidelines and published articles in Google scholar, Pubmed and Science direct of articles up to June 2020. The keywords used for gathering information were listed below.

Keywords: Pharmacy, Current status, Regulations, COVID-19, Future challenges, Recommendations

(C) 2021 The Authors. Published by Innovare Academic Sciences Pvt Ltd. This is an open access article under the CC BY license (http://creativecommons.org/licenses/by/4.0/) DOI: http://dx.doi.org/10.22159/ijap.2021v13i1.39688. Journal homepage: https://innovareacademics.in/journals/index.php/ijap

Speedy peer review was done as the subject of the manuscript was related with pandemic.

\section{INTRODUCTION}

People in every country became exposed to COVID-19 pandemic and not able to find a right solution and strategies to overcome from it. Pharmacy is the most important, dynamic and versatile health care profession in the world, whereas its scope and importance are always being emerging at any situation [1]. Pharmacy professionals (PPs) working proactively for the public even in this pandemic situation Since dependency is high, the responsibility and preference also high for PPs especially in this pandemic situation. The pharmacy zone is an adaptable, developing and progressively different one, which has a huge number of chances for work and administration aspects [2]. PPs are human service experts whose proficient obligations incorporate to protect the individuals by dispensing medicines with prescriptions [3]. It represents the third biggest medicinal services with active gathering in the world and in India there are more than 1,000,000 (1 Million) enrolled PPs working in different positions contributing to the wellness of the country. Pharmacy is being a significant profession, since the Indian government passed the Pharmacy Act 1948 to control the pharmacy stores by following instructions to control the manufacturing, distribution and marketing [4]. Health care in the genuine sense called as pharmacy practice which incorporates; clinical, community and hospital pharmacy. PPs shape an imperative connection between doctors, nurses and the patients in the social community group with an ultimate focus on patient welfare and safety [5]. Pharmacists cannot be only the distributors, but also they need to offer some contributions to the society, including administrations such has patient counselling, guiding and arrangement of medication data to human services, suppliers as well as patients [6]. The pharma industry performed well after the amendment of new monetary changes in India in the mid-1990s till the early 2000s, for example, before the product patent was introduced in India [7]. In educational aspects level of student's outcome in pharmacy also have been increased from the year of 2012 to 2020 and still expected to rise due to its scope. Many of the pharmacy graduates showing potential interest in the research side for drug innovation and development [8]. It has been viewed that pharmacy as a significant job in improving social insurance as they work day and night to keep up a chain of elegant integrity on pharmaceuticals especially during a COVID-19 pandemic. PPs has many roles and responsibilities right from the perspective of regulatory authorities in performing implementation of updated guidelines based on the situation defects [9]

\section{Pharmacy practice}

It includes implementation, evaluation and interpretation of pharmacy orders and prescription dispensing. Pharmacists are responsible for providing patient counselling, provisions for acts and social services required to promote pharmaceutical care in all areas of patient health as a primary care [10]. They are also responsible for the segregation, labelling of drugs and medical devices, by ensuring safety on proper storage of drugs and devices along with maintenance of proper records [11].

According to Supreme Court judgment of $5^{\text {thMarch }} 2020$

- Pharmacy Act is a pre-constitutional act

- There cannot be two regulators

- AICTE act is a general act

- Pharmacy act is a special act

- Pharmacy act is a complete code with pharmacy experts

- Pharmacy Council of India (PCI) alone shall prescribe qualification for pharmacist

- PCI alone shall prescribe norms for pharmacy institutions

- Approval and intake in institutes be decided by PCI alone

- Pharmacy act can regulate not only pharmacy education, but profession also [12]

Pharmacy professions in India

- Pharma industry

- Community pharmacy 
- Pharmaco-vigilance

- Pharmacy education

- Pharma regulatory practice

\section{First pharmaceutical company in India}

Bengal chemical and pharmaceuticals Ltd., was set up as an initiative by the individual, started a laboratory in 1892 by the 'Father of Indian chemistry' Acharya Prafulla Chandra Ray and regarded the country's first pharma company. Bengal chemicals and pharmaceuticals Ltd. has reached profits for a year 2016-17 for the first time after more than six decades [13].

\section{Drug regulation}

India has the world's toughest legislation and laws for manufacture, distribution and sale of medicines. The law enforcement's ability does not translate by strong legislation alone; it also involves strict regulations and accepting effective challenges. There should be one drug inspector for every 50 manufacturing units and one per 200 distribution retailers, according to the regulation set out by the Mashelkar committee $[14,15]$. In most of the state's $30-50 \%$ of the posts remain vacant and the number of posts that exists also is highly inadequate for expanding the pharmacy sector. As per the Mashelkar committee report, 1 drug inspector for 200 retailers was taken into consideration and among the data of All India Organization of Chemists and Druggists (AIOCD), around 8.5 lakh pharmacies is to be taken cognizance, so more than 4250 drug inspectors needed to manage the retail pharmacy segment [16].

\section{Division of responsibilities between CDSCO and SDRA}

\section{Pre-manufacturing}

Central Drugs Standard Control Organization (CDSCO) regulates premanufacturing with the help of expert committees. Their key role in dealing with the two major criteria is:
- Clinical trials (Clinical trial registry, Good Clinical Practices (GCP), inspections, ethics committee and serious adverse events)

- New drug approvals (import and marketing license) [17].

\section{Manufacturing}

State Drug Regulatory Authority (SDRA) is responsible for regulating the manufacture of drug products in the states, whereas CDSCO is responsible for union territories. CDSCO and SDRAs also conduct joint inspections in certain cases [18]. The following terms are necessary for the manufacturing of drug products.

- License (generic and marketing license)

- Inspection of Good Manufacturing Practices (GMP)

- Drug testing and prosecution for non-compliance[19]

\section{Distribution and sale}

SDRA's are responsible for regulating the distribution and sale of drug products in the states, while CDSCO is responsible for union territories. The following terms are necessary for the distribution and sale of drug products.

- License (sale and distribution practices)

- Inspection of Good Distribution Practices (GDP)

- Drug testing and prosecution for non-compliance[20]

\section{Current status}

The current status in pharmacy education, authority functions and future challenges of PPs in all aspects, particularly in this COVID-19 pandemic were addressed. While in the development phase, it has to cross many barriers, not only in the economic level but also involves regulations, duration, process controls, legal hurdles and situational defects [21]. The educational updates were presented in table 1.

Table 1: Statistics of pharmacy education program in India

\begin{tabular}{lll}
\hline Pharmacy program & Number of institutions & Annual intake \\
\hline D Pharm & 3022 & 180,770 \\
B Pharm & 1961 & 125,524 \\
Pharm D & 267 & 8010 \\
M Pharm & 792 & 24,465 \\
Ph. D. in Pharmacy & 31 & 1240 \\
\hline
\end{tabular}

\section{COVID-19 and the impact}

The impact of the SARS-CoV2 outbreak, COVID-19 has exposed the dependence of the Indian pharma sector on china for its Active Pharmaceutical Ingredient API obtainment, since India as well as other countries had decided to stop business contract with china. Gracefully, chain circulation and exportation limitations from India came out because of manpower deficiencies in china's manufacturing plants [22]. This was brought by the isolated arrangements adjusted and embraced by various common governments in china in response to the infection. Supplies were additionally affected by the interruption of coordination, transportation frameworks, confining access and exchange of items to and from ports [23]. More over the customers who are coming for pharmacy stores may be positive for COVID-19 but remain as asymptomatic, so this will impact the pharmacist to get spread, whereas in hospital pharmacy if this same incident happens, then there is an easy chance of getting more spread among the patients who came to hospital since they may be weaker in health and being low immune [24, 25].

Indian government strategies for API stimulation-atmanirbar bharat

The government has announced about promotion of common infrastructure facilities in three 'Bulk Drug Parks' (BDP) with the financial investment of INR 3,000 crore in the next five years. The government will provide grant-in-aid scheme to the states with a maximum limit of INR 1,000 crore per BDP, which having general facilities such as solvent recovery plant, distillation plant, common effluent treatment plant, power and steam units [26]. It will create a Production Linked Incentive (PLI) scheme for promotion of domestic manufacturing of critical Key Starting Materials (KSM), intermediates of drug and Active Pharmaceutical Ingredients (APIs) in the country with the financial implications of INR 6,940 crore for the next eight years [27].

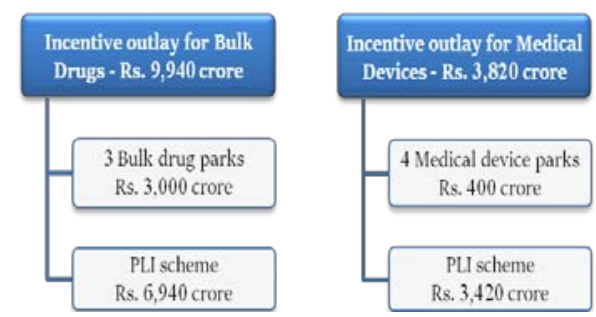

Fig. 1: Incentive details of the proposed scheme [29]

\section{Initiative by the government}

PLI Scheme is open for four months from June 2, 2020 will allow investors to propose the establishment of Greenfield facilities for any of the 53 key drug intermediates and bulk drugs that are hardly 
manufactured in India today [28]. The list includes key ingredients that go into the manufacturing of commonly prescribed medicines like paracetamol, aspirin, metformin, atorvastatin, etc. The total proposed incentive package contains Rs. 13,760 crore, that is segregated for bulk drugs and medical devices were classified below in fig. 1 .

\section{Challenges associated with PPs \\ COVID-19 challenges}

- Millions affected globally

- No cure insight

- Digital (online) education

- Test for Indian strategy and approach

- Expectations in Indian pharmaceutical sector in the global visibility

- Challenges in opportunities

\section{Regulatory challenges}

This segment suffers from the problem of information asymmetry across the different layers of regulatory and enforcement mechanisms. There is a large variance in the quality of drug regulation across states in the country, since each state having their own regulations [30]. Drug inspectors of India who are the key players in drug regulations should be made highly qualified and be well paid to bring about the dignity associated with the huge responsibility. There is a budget constraint with the department for implementation of advanced methods of monitoring the regulations [31].

\section{Pharma industry-future challenges}

There is a huge expectation, price pressure and carefulness in monitoring of vaccine development, especially (Covaxin) for treatment of COVID-19, which is still under the Phase I and II clinical trial in India. There may be a chance of unsatisfactory results occur in Phase III trial, whereas many countries faced the issue on Phase III trial, which resulted failure in vaccine development and outcome [32]. Nowadays there are emerging challenges in the management of process controls during a formulation of pharmaceuticals is the formation of impurities, which are in the form of genotoxic and carcinogenic that are highly toxic and harmful for the patients who were taking medication for the management of diabetes, gastric ulcer and psychosis [33]. There is also a compensation challenge for the loss of Fixed Dose Combination (FDC) drugs in India, since many of the drugs around 344 under this category were banned and withdrawn due to they are therapeutically irrational and produced toxicity to the patients for treatment of chronic diseases like tuberculosis and HIV. So there are still expectations of producing FDCs, into the market for patient beneficence with assurance in the safety and efficacy [34]. The quality of research, drug discovery and development is suboptimal if the money investment is not strengthened.

\section{Digital education}

Holon IQ global education intelligence, a provider estimates that the present education sector size of $\$ 6$ trillion will reach $\$ 10$ trillion by 2030 . Only $3 \%$ of the global education spends is digital platform and by 2025 the digital spend will be $\$ 325$ billion, which is less than $5 \%$ of the global education spend $[35,36]$. The present challenges faced by the government are the seamless delivery of education in the post-covidian direction of digital education, but this will be a far cure for the education disorders in the country [37]. The UGC is in the process of developing a game-changing policy where the universities that have a high 'NAAC' score among the top $100 \mathrm{NIRF}$ rankings will be permitted to offer online programs. This will be a game-changer as the jurisdiction of education will become global and only those universities which are equipped will survive [38].

\section{Recommendations}

Based on the unique situation faced by the every country due to COVID-19, the recommendations were executed below for the PPs:

- The pharma industry needs to get out of the COVID-19 based mindset and start focusing on the needs of the country and strategies to work despite the policy and regulatory challenges.
- Adequate funding should be given by the government to the researchers of PPs for the new drug development and for conducting clinical trials.

- The pharma industry should learn to invest in quality manpower to get the desired outcomes and shift the focus from the product to the patient [39].

- Interpretation of state and central guidelines to protect the public health and disease control management.

- Strengthening the regulations on health care management and professionals to follow strict rules based on the states.

- There should not be a significant dependency for API procurement from china, instead of that, steps to be taken for API supply from own country itself.

- Enabling workflow modifications in principles while handling emergency situations

- To create awareness and educational training programs to safeguard physical and mental health among each individual during this pandemic situation.

- The pharmacognosy and phytopharmacy department should focus on herbal and ayurvedic formulation development to fight against COVID-19 as naturopathy based treatment.

- The positive, believable and evidence based advertisements to be done by the PPs regarding the traditional method of AYUSH based medications to fight against COVID-19.

- The public should consume "Kapasura kudineer" that is readily available in retail pharmacy especially in south India that contains many combinations of herbs that can combat corona virus and other microorganisms, this have shown positive results, since many people got benefited and relieved from COVID-19 in asymptomatic reported positive cases.

- Steps to be taken for e-learning/webinar programs to get more updates from the WHO and health advisory committee for the pharmaceutical development and public health protection.

- Utilization of PPs as second line healers or physicians to diagnose the patient's illness in case of emergency [40].

- Enabling e-prescriptions and home delivery of medicines to the self-isolated individuals during COVID-19 outbreak and older persons by ensuring precautionary measures and safety.

- Advocacy with policy makers and stakeholders needs to be strengthened to get the right regulatory environment that can stimulate growth of the pharmaceutical industry.

\section{CONCLUSION}

The Indian pharmaceutical industry has experienced a wide strategy changes that is expected to affect the execution of national as well as regional level. Although the greater part of the states recovered from the serious issues and gave indications of nearly better execution from the year 2007 to 2011, but there is still an emerging challenges and lack of developments to reach the benchmark when compared to other developed countries. From the overall study, key elements are money investment, educational trainings, awareness programs and recommendations, which is highly required for PPs to expand their roles in bringing up navigation for greater development in quality of pharmaceuticals to defend any challenges, health issues and deadly disease like COVID-19, so ultimately the recognition will reach globally for PPs in India. The money investment from the government or funding agency should come forward and contribute to the researchers in bringing up the development for better quality pharmaceuticals to defend any health issues and deadly diseases like COVID-19 that affect from personally to globally.

\section{FUNDING}

Nil

\section{AUTHORS CONTRIBUTIONS}

All authors contributed equally. 


\section{CONFLICTS OF INTERESTS}

None

\section{REFERENCES}

1. Kasthuri A. Challenges to healthcare in India-the five A's. Indian J Community Med 2018;43:141-3.

2. Basak SC, Sathyanarayana D. Community pharmacy practice in India: past, present and future. South Med Rev 2009;2:11-4.

3. Rotta I, Salgado TM. Ensuring consistent reporting of clinical pharmacy services to enhance reproducibility in practice: an improved version of DEPICT.J Evaluation Clin Practice 2015;21:584-90.

4. Mohanan M, Hay K, Mor N. Quality of health care in India: challenges, priorities, and the road ahead. Health Affairs 2016;35:1753-8.

5. MoHFW. Home; 2020. Available from: https://www. mohfw.gov.in/. 05 Aug 2020]

6. Lakshminarayanan S. Role of government in public health: current scenario in India and future scope. J Family Community Med 2016;18:26-30.

7. Kalaiselvan V, Srivastava S, Singh A. Pharmacovigilance in India: present scenario and future challenges. Drug Safety 2019;42:339-46.

8. Palsokar G, Tajne M. Postgraduate research in pharmaceutical sciences in India: a survey of select pharmacy professionals. Int J Curr Pharm Res 2017;9:161-4.

9. Jose J, Rafeek N. R pharmacovigilance in India in comparison with the USA and European Union: challenges and perspectives. Ther Innovation Regulatory Sci 2019;53:781-6.

10. Mohanan M, Hay K, Mor N. Quality of health care in India: challenges, priorities, and the road ahead. Health Affairs 2016;35:1753-8.

11. Vignesh M, Ganesh GNK. Current status, challenges and preventive strategies to overcome data integrity issues in the pharmaceutical industry. Int J Appl Pharm 2020;12:19-23.

12. Supreme court of India, Union of India vs. M. V. Mohanan Nair 2020. Available from: https://indiankanoon.org/doc/55062525/ [Last accessed on 05 Aug 2020]

13. Kishore J. Legislation and health promotion in India. Rev Global Med Healthcare Res 2012;37:75-87.

14. Ramalingam Peraman, Hari Hara Theja Dugga. Need for the refinement of licensing procedure for pharmacists in India. J Young Pharm 2016;8:293.

15. Lakshminarayanan S. Role of government in public health: current scenario in India and future scope. J Family Community Med 2016;18:26-30.

16. Peter Roderick, Rushikesh Mahajan. India should introduce a new drugs act. Lancet 2014;383:203-6.

17. Daniel Bennett, Wesley Yin. The market for high-quality medicine: retail chain entry and drug quality in India. Rev Economics Statistics 2019;101:76-90.

18. Thaker Z, Jethva K, Bhatt D, Zaveri M, Deshpande S. Orphan drugs: overview and regulatory review process. Int J Pharm Sci Res 2019;10:505-18.

19. Agarwal Praveen, Bhandary Deepak, Rasheed Abdul. Drug approval procedure in India (CDSCO). Res Rev: J Drug Design Discovery 2015;2:20-6.

20. Daniel Bennett, Wesley Yin. The market for high-quality medicine: retail chain entry and drug quality in India. Rev Economics Statistics 2019;101:76-90.

21. Pravat Kumar J. Impact of pandemic COVID-19 on education in India. Int J Curr Res 2020;12:12582-6.

22. World Health Organization. Coronavirus disease (COVID-19) outbreak situation; 2020 Available from: https:// www.who.int/emergencies/diseases/novel-coronavir us-2019. [Last accessed on 10 Aug 2020].
23. Hedima EW, Adeyemi MS, Ikunaiye NY. Community pharmacists: on the frontline of health service against COVID19 in LMICs. Res Soc Administrative Pharm 2020;19:30381-8.

24. Carolina Oi Lam Ung. Community pharmacist in public health emergencies: quick to action against the coronavirus 2019nCoV outbreak. Res Soc Administrative Pharm 2020;16:583-6.

25. Mukattash TL, Jarab AS. Pharmacists' perception of their role during COVID-19:a qualitative content analysis of posts on facebook pharmacy groups in Jordan. Pharm Practice 2020;18:1900.

26. Shrimali, Gireesh, Retna Kumar, Aravind. Battery storage manufacturing in India: a strategic perspective; 2020. Available from: https://ssrn.com/abstract=3616404 [Last accessed on 10 Aug 2020]

27. Usha Sharma. Pharma cos should develop strategies to develop APIs and making India self-reliant: Dr Eswara Reddy. Express pharma; 2020. Available from: https://www. expresspharma.in/latest-updates/pharma-cos-should-developstrategies-to-develop-apis-and-making-india-self-reliant-dreswara-reddy/ [Last accessed on 10 Aug 2020]

28. Department of pharmaceuticals. PLI Scheme for Pharmaceuticals and Medical devices; 2020. Available from https://pharmaceuticals.gov.in/schemes\#: :text=Download\% $20(1.6 \% 20 \mathrm{MB})-$

,Production\%20Linked\%20Incentive\%20(PLI)\%20Scheme\%2 0for\%20promotion\%20of\%20domestic\%20manufacturing,Pr omotion\%20of\%20Bulk\%20Drug\%20Parks. [Last accessed on 10 Aug 2020]

29. Mansukh Mandaviya. Covid-19: centre chalks out four schemes to boost production of bulk drugs and medical devices; 2020. Available from: https://economictimes.indiatimes.com/news/economy/policy/co vid-19-centre-chalks-out-four-schemes-to-boost-production-ofbulk-drugs-and-medical-

devices/articleshow/74867468.cms?from=mdr [Last accessed on 10 Aug 2020]

30. Anyachebelu O, Aluh D. Pharmacists compliance to practice regulations and good professional practice: a case study of Nigerian community pharmacists. Int J Pharm Pharm Sci 2018;10:98-104.

31. Shahrawat R, Rao KD. Insured yet vulnerable: out-of-pocket payments and India's poor. Health Policy Plan 2012;27:213-21.

32. Singhal T. A review of coronavirus disease-2019 (COVID-19). Indian J Pediatrics 2020;87:281-6.

33. Mackey. Fit-for-purpose?-challenges and opportunities for applications of blockchain technology in the future of healthcare. BMC Med 2019;17:1-17.

34. Vignesh M, Ganesh GNK. Fixed dose combinations banned in India-a review. J Pharm Sci Res 2020;12:987-91.

35. Aiswarya Vijayan. Digital India-a roadmap to sustainability. Int J Innovative Technol Exploring Engineering 2019;8:571-6.

36. Nedungadi PP, Menon R, Gutjahr G, Erickson L, Raman R. Towards an inclusive digital literacy framework for digital India. Education Training 2018;60:516-28.

37. Snyder ME, Jaynes HA. Factors associated with comprehensive medication review completion rates: a national survey of community pharmacists. Res Soc Administrative Pharm 2020;16:673-80.

38. Rajubhai L Pargi. Implication and impact of digital education system in India. Int $\mathrm{J}$ Humanities Soc Sci: Insights Transformations 2019;4:1-6.

39. Vignesh M, Ganesh GNK. Generic prescription in India-a review. Asian J Pharm Clin Res 2020;13:20-4.

40. Nandini G, Anitha K. An intelligent pharmacy and health care services. J Critical Rev 2020;7:1820-6. 